Simone Machado GUIMARÃES ${ }^{1}$

Valéria Nobre Leal de Souza OLIVA $^{2}$

Camila Aparecida de Almeida MAIA ${ }^{3}$

Luciana Del Rio Pinoti CIARLINI ${ }^{2}$

Silvia Helena Venturolli PERRI $^{2}$

Alexandre Redson Soares da SILVA ${ }^{2}$

Daniela Boaventura de OLIVEIRA²

Maria Carolina Ribeiro VIVAN $^{2}$

\section{Correspondência para:}

Simone Machado Guimarães

Rua Santa Rosa, 540. 16400-455, Lins/SP email:si vetg@yahoo.com.br

Recebido para publicação: 30/08/2006 Aprovado para publicação: 23/08/2007

\title{
Correlação de diferentes períodos de jejum com níveis séricos de cortisol, glicemia plasmática, estado clínico e equilíbrio ácido-base em cães submetidos à anestesia geral inalatória
}

1 - Faculdade de Medicina Veterinária e Zootecnia da Universidade Estadual Paulista Júlio de Mesquita Filho, Botucatu-SP

2 - Faculdade de Odontologia de Araçatuba da Universidade Estadual Paulista Júlio de Mesquita Filho, Araçatuba-SP

3 - Faculdade de Medicina da Universidade Estadual Paulista Júlio de Mesquita Filho, Botucatu-SP

\section{Resumo}

Este estudo correlacionou os tempos de jejum sólido pré-anestésico com alterações nos níveis de glicemia plasmática, cortisol sérico, estado clínico e equilíbrio ácido-base em cães submetidos a anestesia geral inalatória. Utilizaram-se oito animais, adultos, sem raça definida, distribuídos de acordo com o período de jejum sólido: Grupo 1 (12 horas), Grupo 2 (18 horas) e Grupo 3 (24 horas). Foi acompanhado o esvaziamento do conteúdo gástrico e em seguida, todos animais foram submetidos ao mesmo procedimento anestésico. Freqüência cardíaca e respiratória, temperatura retal, tempo de reperfusão capilar, grau de hidratação e pressão arterial não-invasiva foram mensurados previamente à administração de acepromazina, 10 minutos decorridos da mesma e a cada 10 minutos durante a manutenção anestésica, incluindo-se $\mathrm{ETCO}_{2}$; valores hemogasométricos $\left(\mathrm{pH}, \mathrm{PaCO}_{2}, \mathrm{PaO}_{2}\right.$, $\mathrm{HCO}_{3}, \mathrm{CO}_{2}$ total, $\mathrm{SatO}_{2}$, déficit de base), glicêmicos e de cortisol sérico foram avaliados previamente à MPA e a cada trinta minutos durante a manutenção anestésica. No período de recuperação anestésica, novas dosagens glicêmicas e de cortisol foram realizadas. Constataram-se poucas alterações cardiocirculatórias e respiratórias durante a anestesia, não havendo interferência dos diferentes tempos de jejum. Os animais com 12 horas de jejum pré-anestésico apresentaram glicemia mais elevada do que os demais grupos, no período de recuperação anestésica. As concentrações de cortisol não foram afetadas pelo jejum. O jejum pré-anestésico sólido, independente do tempo de duração, caracterizou um quadro de discreta alcalose respiratória. Todos os animais apresentaram-se em bom estado clínico nos três grupos. Recomendase jejum pré-anestésico sólido de 18 horas para garantir ausência completa de conteúdo alimentar sólido no estômago.

\section{Introdução}

Os procedimentos anestésicos, seguidos ou não de ato cirúrgico, devem ser precedidos de jejum sólido e hídrico, permitindo maior segurança ao ato clínicocirúrgico. Esta conduta tem a finalidade de reduzir a ocorrência de êmese ou de refluxo gástrico durante a anestesia diminuindo, conseqüentemente, o risco de asfixia ou pneumonite por aspiração.

O jejum é preconizado de acordo com a espécie animal e ocorrem variações entre os autores quanto ao período ideal de jejum sólido e líquido recomendado para cães. Períodos prolongados de jejum podem desencadear hipoglicemia, estresse, desidratação, acidose metabólica, fome, sede 
e desconforto ao paciente ${ }^{1,2,3}$ sendo indesejável, principalmente em temperaturas altas e após pré-medicações antisialogogas ${ }^{1}$. Em alguns estudos realizados, a glicemia não apresentou diferenças significativas frente a diferentes períodos de jejum pré-anestésico preconizados. ${ }^{4,5}$ Em crianças, o jejum prolongado (8-12 horas) foi associado a notáveis diminuições da pressão sangüínea arterial durante anestesia com halotano. ${ }^{6}$ Pickrell et al. $^{7}$ comprovaram que, em cães, quanto maior o período de jejum, menores são os valores de $\mathrm{pH}, \mathrm{PaCO}_{2}$ e $\mathrm{BE}$, considerando a ocorrência de acidose moderada de origem metabólica.

Em relação ao tempo de esvaziamento gástrico, este é variável entre alimentos com alto teor de umidade (4 a 6 horas) e secos (14 a 16 horas) em cães e gatos, observandose também variações individuais. ${ }^{8}$ As carnes enlatadas e cereais secos presentes no estômago de cães são digeridos após 10 horas e a água após 52 minutos de ingestão, com observações de variações individuais. No entanto, Evans ${ }^{10}$ afirma que a presença de alimento no estômago de cães acima de 10 horas após a refeição depende da consistência do alimento. Dor, estresse e as condições mentais dos animais (animais inquietos ou ansiosos) podem atrasar o esvaziamento gástrico aumentando assim, o risco de regurgitação. ${ }^{8,11}$
Portanto, os principais objetivos deste trabalho foram: correlacionar os tempos de jejum sólido pré-anestésico com alterações nos níveis de glicemia, cortisol sérico, estado clínico do animal e equilíbrio ácido-base; avaliar as alterações de valores de parâmetros cardiocirculatórios e respiratórios ocorridos após diferentes períodos de jejum pré-anestésico em cães submetidos à anestesia geral inalatória e, propor um período de jejum pré-anestésico mais preciso para a espécie canina que traga o mínimo de alterações fisiológicas e que não interfira na segurança de uma anestesia geral inalatória.

\section{Material e Método}

Foram utilizados oito animais, hígidos, machos ou fêmeas, sem raça definida, com peso corporal de 13,8 a 24 quilos. Os animais foram distribuídos em três grupos, de acordo com o tempo de jejum sólido: Grupo 1 (12 horas), Grupo 2 (18 horas) e Grupo 3 (24 horas); preconizando-se jejum hídrico de duas horas em todos os grupos. Foi realizada a avaliação radiográfica da quantidade de material estomacal (sólido e/ ou líquido) baseada na classificação através de escores (Quadro 1), acompanhando-se o esvaziamento do conteúdo gástrico durante o período de jejum estudado. Em

\begin{tabular}{|c|c|}
\hline Escores & Significado \\
\hline 4 & $\begin{array}{c}\text { Repleção estomacal sólida e/ou } \\
\text { líquida com } 100 \text { a } 80 \% \text { de conteúdo }\end{array}$ \\
\hline 3 & $\begin{array}{c}\text { Repleção estomacal sólida e/ou } \\
\text { líquida com } 79 \text { a } 50 \% \text { de conteúdo }\end{array}$ \\
\hline 2 & $\begin{array}{c}\text { Repleção estomacal sólida e/ou } \\
\text { líquida com } 49 \text { a } 15 \% \text { de conteúdo }\end{array}$ \\
\hline 1 & $\begin{array}{c}\text { Repleção estomacal sólida ausente e } \\
\text { líquida abaixo de } 15 \% \text { de conteúdo }\end{array}$ \\
\hline 0 & Repleção estomacal sólida e líquida \\
ausente
\end{tabular}

Quadro 1 - Determinação do escore radiográfico baseado conforme a classificação 
seguida, realizou-se exame pré-anestésico, aferindo-se os seguintes parâmetros (M0): temperatura retal, freqüência cardíaca e respiratória, tempo de reperfusão capilar, grau de hidratação, pressão arterial nãoinvasiva (sistólica, média e diastólica). Foram colhidas amostras sangüíneas para dosagem glicêmica e de cortisol e análise hemogasométrica arterial. O procedimento anestésico escolhido foi: acepromazina $(0,05$ $\mathrm{mg} / \mathrm{kg}$, via intravenosa) e após 15 minutos, indução anestésica com tiopental sódico (12 $\mathrm{mg} / \mathrm{kg}$, via intravenosa). A manutenção anestésica foi realizada com halotano, com fluxo diluente de oxigênio de $100 \%$ durante 60 minutos.

Os parâmetros anteriormente avaliados foram mensurados 10 minutos decorridos da MPA (M1) e a cada 10 minutos durante a manutenção da anestesia (M2 a M8), incluindo-se a pressão expirada de dióxido de carbono. Novas amostras sangüíneas para análise hemogasométrica e dosagem glicêmica e de cortisol foram colhidas durante a manutenção anestésica, a cada 30 minutos (M5 e M8) e; quando decorridas duas horas do final da vaporização anestésica (MFi) realizou-se novamente a dosagem glicêmica e de cortisol.

A dosagem glicêmica plasmática foi realizada a partir de amostras sangüíneas de $3 \mathrm{ml}$ de sangue venoso, colhidas por venopunção, em tubo de vidro contendo o anticoagulante flureto de sódio e, posteriormente centrifugadas. Para a determinação de glicose foi usado o método enzimático colorimétrico e, a leitura realizada através de um espectrofotômetro (modelo E-205D acoplado ao sistema cinético modelo SB-215P, CELM $\left.{ }^{\circledR}\right)$. Para a dosagem sérica de cortisol, amostras de sangue venoso foram colhidas por venopunção e mantidas em repouso para coagulação e posterior centrifugação. Em seguida, as amostras foram acondicionadas em tubos siliconizados e conservados em freezer até o momento da dosagem quantitativa, esta última realizada através da técnica de radioimunoensaio.
As variáveis que apresentaram distribuição normal foram analisadas por meio da análise de variância, sendo as médias comparadas através do teste de Tukey e as variáveis que não apresentaram distribuição normal foram analisadas usando-se o teste de Friedman, seguido do teste de Dunn para comparações múltiplas. $\mathrm{O}$ estabelecimento de escore foi analisado através do teste exato de Fisher. As estatísticas foram consideradas significativas quando $\mathrm{p}<0,05$.

\section{Resultados, Discussão e Conclusões}

Durante a manutenção anestésica observou-se, nos três grupos, certa estabilidade da freqüência cardíaca, respiratória e presença de hipotensão arterial (Tabela 1). Friesen, Wurl e Friesen ${ }^{6}$ associaram o jejum prolongado (8 a 12 horas) com notáveis diminuições da pressão arterial durante anestesia com halotano em crianças, de maneira similar ao ocorrido neste estudo ainda que com diferentes tempos de jejum (12, 18 e 24 horas).

No momento basal (M0), observouse nos três grupos que a $\mathrm{PaCO}_{2}$ (Tabela 3) apresentou valores médios abaixo do normal levando a uma alcalemia e à redução das concentrações de $\mathrm{HCO}_{3}$ (mecanismo compensatório). Portanto, houve a ocorrência de discreta alcalose respiratória (compensada), justificada pela hiperventilação em decorrência da excitação apresentada pelo animal (ansiedade, estímulo cortical, medo). ${ }^{3}$

Os valores médios de $\mathrm{pH}, \mathrm{PaCO}_{2} \mathrm{e}$ $\mathrm{BE}$ não apresentaram diferenças estatísticas com 12, 18 e 24 horas de jejum préanestésico (Tabela 3). Já Pickrell et al. ${ }^{7}$ comprovaram que quanto maior o período de jejum, menores os valores das respectivas variáveis, considerando-se a ocorrência de acidose metabólica.

Phillips, Daborn e $\mathrm{Hatch}^{12}$ relatam ocorrência de desidratação em pequena intensidade em jejuns de 4 horas, sendo significativa com períodos maiores, entretanto, neste estudo, todos os animais apresentaram-se hidratados de acordo com 
Tabela 1 - Valores médios e erro padrão da média de parâmetros cardiovasculares e respiratórios de cães submetidos a diferentes períodos de jejum

\begin{tabular}{|c|c|c|c|c|c|c|c|c|c|c|}
\hline Variáveis & & M0 & M1 & M2 & M3 & M4 & M5 & M6 & M7 & M8 \\
\hline \multirow[t]{3}{*}{ FC } & G1 & $99 \pm 6 \mathrm{aA}$ & $97 \pm 13 \mathrm{aA}$ & $106 \pm 8 \mathrm{aA}$ & $91 \pm 5 \mathrm{aA}$ & $91 \pm 7 \mathrm{aA}$ & $90 \pm 4 \mathrm{aA}$ & $92 \pm 6 \mathrm{aA}$ & $89 \pm 4 a A$ & $85 \pm 3 \mathrm{aA}$ \\
\hline & G2 & $104 \pm 5 \mathrm{abA}$ & $83 \pm 5 \mathrm{cA}$ & $117 \pm 4 \mathrm{aA}$ & $96 \pm 5 b c A$ & $89 \pm 6 \mathrm{bcA}$ & $93 \pm 4 \mathrm{bcA}$ & $88 \pm 5 b c A$ & $85 \pm 5 \mathrm{cA}$ & $94 \pm 6 \mathrm{bcA}$ \\
\hline & G3 & $96 \pm 3 \mathrm{bA}$ & $92 \pm 5 \mathrm{bA}$ & $115 \pm 7 \mathrm{aA}$ & $97 \pm 5 \mathrm{abA}$ & $88 \pm 6 \mathrm{bA}$ & $93 \pm 8 \mathrm{bA}$ & $85 \pm 5 b A$ & $84 \pm 5 \mathrm{bA}$ & $89 \pm 7$ bA \\
\hline \multirow[t]{3}{*}{ PAS } & G1 & $129 \pm 2$ aA & $112 \pm 2 \mathrm{bA}$ & $95 \pm 3 \mathrm{cA}$ & $81 \pm 4 d A$ & $87 \pm 5 \mathrm{cdA}$ & $89 \pm 5 \mathrm{cdA}$ & $83 \pm 4 \mathrm{cdA}$ & $83 \pm 3 \mathrm{cdA}$ & $87 \pm 4 \mathrm{cdA}$ \\
\hline & $\mathrm{G} 2$ & $128 \pm 6 \mathrm{aA}$ & $110 \pm 4 \mathrm{abA}$ & $96 \pm 2 \mathrm{bcA}$ & $89 \pm 5 \mathrm{cA}$ & $86 \pm 3 \mathrm{cA}$ & $95 \pm 6 \mathrm{bcA}$ & $86 \pm 4 \mathrm{cA}$ & $84 \pm 3 \mathrm{cA}$ & $87 \pm 3 \mathrm{cA}$ \\
\hline & G3 & $127 \pm 7 \mathrm{aA}$ & $108 \pm 4 \mathrm{abA}$ & $99 \pm 5 \mathrm{bcA}$ & $86 \pm 5 \mathrm{cdA}$ & $84 \pm 4 \mathrm{cdA}$ & $83 \pm 3 \mathrm{cdA}$ & $78 \pm 3 \mathrm{dA}$ & $83 \pm 3 \mathrm{cdA}$ & $85 \pm 3 \mathrm{cdA}$ \\
\hline \multirow[t]{3}{*}{ PAM } & G1 & $84 \pm 4 \mathrm{aA}$ & $70 \pm 4 \mathrm{abA}$ & $64 \pm 4 \mathrm{bcA}$ & $58 \pm 3 \mathrm{bcA}$ & $59 \pm 3 \mathrm{bcA}$ & $61 \pm 3 \mathrm{bcA}$ & $56 \pm 1 \mathrm{cA}$ & $54 \pm 2 \mathrm{cA}$ & $55 \pm 4 c \mathrm{~A}$ \\
\hline & $\mathrm{G} 2$ & $81 \pm 5 \mathrm{aA}$ & $66 \pm 3 \mathrm{bA}$ & $64 \pm 3 \mathrm{bA}$ & $59 \pm 2 \mathrm{bA}$ & $59 \pm 2 \mathrm{bA}$ & $68 \pm 5 \mathrm{abA}$ & $55 \pm 2 \mathrm{bA}$ & $57 \pm 3 \mathrm{bA}$ & $57 \pm 3 \mathrm{bA}$ \\
\hline & G3 & $83 \pm 4 a A$ & $66 \pm 5 \mathrm{bA}$ & $68 \pm 4 \mathrm{bA}$ & $59 \pm 5 \mathrm{bA}$ & $59 \pm 3 b A$ & $56 \pm 3 \mathrm{bA}$ & $55 \pm 3 \mathrm{bA}$ & $55 \pm 2 \mathrm{bA}$ & $60 \pm 2 \mathrm{bA}$ \\
\hline \multirow[t]{3}{*}{ PAD } & G1 & $35 \pm 2 \mathrm{aB}$ & $34 \pm 2 \mathrm{aA}$ & $31 \pm 3 \mathrm{abA}$ & $26 \pm 2 b c A$ & $27 \pm 2 \mathrm{bcA}$ & $30 \pm 3 \mathrm{abA}$ & $26 \pm 2 \mathrm{bcA}$ & $23 \pm 3 \mathrm{cA}$ & $25 \pm 2 \mathrm{bcA}$ \\
\hline & $\mathrm{G} 2$ & $43 \pm 6 \mathrm{aAB}$ & $27 \pm 2 \mathrm{bB}$ & $30 \pm 3 \mathrm{bA}$ & $26 \pm 2 b A$ & $24 \pm 2 \mathrm{bA}$ & $30 \pm 3 \mathrm{bA}$ & $25 \pm 2 \mathrm{bA}$ & $26 \pm 3 b A$ & $27 \pm 2 \mathrm{bA}$ \\
\hline & G3 & $48 \pm 2 \mathrm{aA}$ & $33 \pm 2 \mathrm{bAB}$ & $32 \pm 3 \mathrm{bA}$ & $27 \pm 1 b A$ & $25 \pm 2 \mathrm{bA}$ & $27 \pm 4 \mathrm{bA}$ & $25 \pm 1 \mathrm{bA}$ & $27 \pm 2 \mathrm{bA}$ & $25 \pm 2 \mathrm{bA}$ \\
\hline \multirow[t]{3}{*}{$f$} & G1 & $48 \pm 5$ aA & $39 \pm 3$ aA & $17 \pm 3 \mathrm{bA}$ & $15 \pm 2 \mathrm{bA}$ & $14 \pm 2 \mathrm{bA}$ & $15 \pm 2 \mathrm{bA}$ & $18 \pm 2 b A$ & $17 \pm 2 \mathrm{bA}$ & $19 \pm 1 \mathrm{bA}$ \\
\hline & $\mathrm{G} 2$ & $53 \pm 10 \mathrm{aA}$ & $47 \pm 8 \mathrm{aA}$ & $14 \pm 3 \mathrm{bA}$ & $13 \pm 1 \mathrm{bA}$ & $14 \pm 2 \mathrm{bA}$ & $14 \pm 2 \mathrm{bA}$ & $15 \pm 2 \mathrm{bA}$ & $16 \pm 2 \mathrm{bA}$ & $17 \pm 2 \mathrm{bA}$ \\
\hline & G3 & $39 \pm 4 \mathrm{aA}$ & $61 \pm 20 \mathrm{aA}$ & $16 \pm 2 \mathrm{bA}$ & $14 \pm 1 b A$ & $15 \pm 1 \mathrm{bA}$ & $16 \pm 2 \mathrm{bA}$ & $16 \pm 2 \mathrm{bA}$ & $19 \pm 3 \mathrm{bA}$ & $19 \pm 4 \mathrm{bA}$ \\
\hline
\end{tabular}

FC = freqüência cardíaca, PAS = pressão arterial sistólica, PAM = pressão arterial média, PAD=pressão arterial diastólica, $f=$ freqüência respiratória; letras maiúsculas diferentes indicam diferenças significativas entre grupos; letras minúsculas diferentes indicam diferenças significativas entre momentos de um mesmo grupo.

Tabela 2 - Valores médios e erro padrão da média de glicemia e cortisol em cães submetidos a diferentes períodos de jejum

\begin{tabular}{|c|c|c|c|c|c|}
\hline Variáveis & & M0 & M5 & M8 & MFi \\
\hline Glicose & G1 & $82,25 \pm 2,03 \mathrm{bA}$ & $74,63 \pm 1,86 \mathrm{cA}$ & $78,50 \pm 2,25 \mathrm{bcA}$ & $92,71 \pm 2,06$ aA \\
\hline \multirow[t]{2}{*}{$(\mathrm{mg} / \mathrm{dl})$} & $\mathrm{G} 2$ & $82,88 \pm 2,95 \mathrm{aA}$ & $77,75 \pm 3,82 \mathrm{aA}$ & $78,88 \pm 3,71 \mathrm{aA}$ & $80,13 \pm 2,31 \mathrm{aB}$ \\
\hline & G3 & $78,25 \pm 2,16 \mathrm{aA}$ & $71,38 \pm 2,92 \mathrm{bA}$ & $70,57 \pm 4,20 \mathrm{bA}$ & $80,13 \pm 2,21 \mathrm{aB}$ \\
\hline Cortisol & G1 & $1,12 \pm 0,37 \mathrm{aA}$ & $0,76 \pm 0,12 \mathrm{aA}$ & $0,64 \pm 0,10 \mathrm{aA}$ & $0,51 \pm 0,13 \mathrm{aA}$ \\
\hline \multirow[t]{2}{*}{$(\mu \mathrm{g} / \mathrm{dl})$} & $\mathrm{G} 2$ & $1,85 \pm 0,60 \mathrm{aA}$ & $0,53 \pm 0,21 a \mathrm{~A}$ & $0,56 \pm 0,15 a \mathrm{~A}$ & $0,48 \pm 0,18 \mathrm{aA}$ \\
\hline & G3 & $0,97 \pm 0,19 \mathrm{aA}$ & $1,33 \pm 0,97 \mathrm{aA}$ & $0,97 \pm 0,67 \mathrm{aA}$ & $0,29 \pm 0,06 \mathrm{aA}$ \\
\hline
\end{tabular}

Letras maiúsculas diferentes indicam diferenças significativas entre grupos; letras minúsculas diferentes indicam diferenças significativas entre momentos de um mesmo grupo.

a avaliação clínica da hidratação, nos diferentes tempos de jejum.

Neste estudo, os valores médios de glicemia indicaram normoglicemia em todos os momentos de avaliação (Tabela 2), podendo-se verificar que o jejum prolongado não ocasionou hipoglicemia. Somente os animais 1 e 2 apresentaram hipoglicemia durante a manutenção anestésica nos grupos G2 e G3, confirmando-se assim a baixa incidência de hipoglicemia em decorrência do jejum pré-anestésico ${ }^{12}$. A incidência de hipoglicemia durante a anestesia é de 0 a $30 \%{ }^{12}$. Neste estudo observou que o ambiente, a manipulação, a colheita por venopunção e a duração do jejum não 
Tabela 3 - Valores médios e erro padrão da média de hemogasometria em cães submetidos a diferentes períodos de jejum

\begin{tabular}{|c|c|c|c|c|}
\hline Variáveis & & Mo & M5 & M8 \\
\hline \multirow[t]{3}{*}{$\mathrm{pH}$} & G1 & $7,47 \pm 0,01 \mathrm{aA}$ & $7,35 \pm 0,02 \mathrm{bA}$ & $7,36 \pm 0,02 \mathrm{bA}$ \\
\hline & $\mathrm{G} 2$ & $7,47 \pm 0,01 \mathrm{aA}$ & $7,37 \pm 0,01 \mathrm{cA}$ & $7,40 \pm 0,02 \mathrm{bA}$ \\
\hline & G3 & $7,47 \pm 0,01 \mathrm{aA}$ & $7,36 \pm 0,02 \mathrm{bA}$ & $7,36 \pm 0,02 \mathrm{bA}$ \\
\hline $\mathrm{PaCO}_{2}$ & G1 & $19,41 \pm 1,49 \mathrm{bA}$ & $30,94 \pm 3,23 \mathrm{aA}$ & $31,05 \pm 2,67 \mathrm{aA}$ \\
\hline \multirow[t]{2}{*}{$(\mathrm{mmHg})$} & G2 & $20,94 \pm 1,65 \mathrm{bA}$ & $35,10 \pm 2,45 \mathrm{aA}$ & $31,38 \pm 1,95 \mathrm{aA}$ \\
\hline & G3 & $19,85 \pm 1,61 \mathrm{bA}$ & $31,93 \pm 1,69 \mathrm{aA}$ & $33,07 \pm 1,64 a \mathrm{~A}$ \\
\hline $\mathrm{PaO}_{2}$ & G1 & $112,75 \pm 8,27 \mathrm{bA}$ & $321,95 \pm 16,93 \mathrm{aA}$ & $305,08 \pm 33,86 \mathrm{aA}$ \\
\hline \multirow[t]{2}{*}{$(\mathrm{mmHg})$} & G2 & $101,59 \pm 13,40 \mathrm{bA}$ & $283,74 \pm 17,65 \mathrm{aA}$ & $279,38 \pm 20,58 \mathrm{aA}$ \\
\hline & G3 & $107,75 \pm 10,05 \mathrm{bA}$ & $286,89 \pm 17,19 \mathrm{aA}$ & $236,36 \pm 37,77 \mathrm{aA}$ \\
\hline $\mathrm{HCO}_{3}$ & G1 & $14,09 \pm 1,19 \mathrm{bA}$ & $17,04 \pm 1,61 \mathrm{aA}$ & $17,35 \pm 1,28 \mathrm{aA}$ \\
\hline \multirow[t]{2}{*}{$(\mathrm{mmol} / \mathrm{l})$} & G2 & $15,36 \pm 1,42 \mathrm{bA}$ & $20,11 \pm 1,38 \mathrm{aA}$ & $19,24 \pm 0,88 \mathrm{aA}$ \\
\hline & G3 & $14,30 \pm 1,31 \mathrm{bA}$ & $18,03 \pm 1,19 \mathrm{aA}$ & $18,89 \pm 0,83 \mathrm{aA}$ \\
\hline $\mathrm{BE}$ & G1 & $-6,23 \pm 1,15 \mathrm{aA}$ & $-6,75 \pm 1,21 \mathrm{aA}$ & $-6,36 \pm 1,02 \mathrm{aA}$ \\
\hline \multirow[t]{2}{*}{$(\mathrm{mmol} / \mathrm{l})$} & G2 & $-5,13 \pm 1,36 \mathrm{aA}$ & $-4,03 \pm 1,23 \mathrm{aA}$ & $-3,88 \pm 0,89 a A$ \\
\hline & G3 & $-6,11 \pm 1,17 \mathrm{aA}$ & $-5,84 \pm 1,25 \mathrm{aA}$ & $-4,99 \pm 0,88 \mathrm{aA}$ \\
\hline $\mathrm{SatO}_{2}$ & G1 & $97,96 \pm 0,61 \mathrm{bA}$ & $99,70 \pm 0,04 \mathrm{aA}$ & $99,25 \pm 0,48 \mathrm{abA}$ \\
\hline \multirow[t]{2}{*}{ (\%) } & G2 & $96,20 \pm 1,56 \mathrm{bA}$ & $99,61 \pm 0,04 \mathrm{aA}$ & $99,64 \pm 0,07 \mathrm{aA}$ \\
\hline & G3 & $97,25 \pm 0,99 \mathrm{aA}$ & $99,61 \pm 0,05 \mathrm{aA}$ & $98,83 \pm 0,55 \mathrm{aA}$ \\
\hline
\end{tabular}

pH = potencial hidrogeniônico do sangue arterial, $\mathrm{PaCO}_{2}=$ pressão parcial de dióxido de carbono, $\mathrm{PaO}_{2}=$ pressão parcial de

oxigêniol, $\mathrm{HCO}_{3}=$ concentração de bicarbonato, $\mathrm{BE}=$ déficit de base, $\mathrm{SatO}_{2}=$ saturação de oxigênio na hemoglobina; letras maiúsculas diferentes indicam diferenças significativas entre grupos; letras minúsculas diferentes indicam diferenças significativas entre momentos de um mesmo grupo.

interferiram na glicemia no momento prévio à MPA (M0).

Alguns estudos mostraram que a anestesia, acompanhada ou não de cirurgia, e o manuseio do paciente produz uma típica resposta ao estresse com alterações hormonais e metabólicas nos animais e homens, incluindo elevação dos valores glicêmicos. ${ }^{3,13,14,15,16}$ Porém, neste estudo os valores significativamente reduzidos da glicemia observados ao longo da manutenção anestésica nos grupos G1 e G3 (Tabela 2) frente ao momento basal (M0) indicaram que os fármacos utilizados e a venopunção não interferiram nas respostas neuroendócrinas ao estresse. Já as alterações significativas da glicemia observadas no período de recuperação anestésica podem ser justificadas pelo despertar anestésico e manipulação do animal para colheita do material biológico. Comparando-se os grupos, observou-se que a glicemia do grupo G1 foi significativamente maior que os demais grupos no momento de recuperação anestésica. Segundo Nogueira et $a 1 .{ }^{5}$, os diferentes tempos de jejum alimentar não apresentaram diferenças em relação às glicemias pré e pós-anestésica nem alteraram o período de recuperação anestésica. 
Os valores de cortisol sérico não diferiram estatisticamente entre os grupos ou dentro de um mesmo grupo (Tabela 2). Os valores médios apresentaram-se dentro do limite de referência para as concentrações basais $(0,5-6,0 \mu \mathrm{g} / \mathrm{dl})$ por este mesmo método, com exceção do grupo G3 no período de recuperação anestésica.

Notou-se que a duração do jejum não afetou as concentrações séricas de cortisol no momento prévio à MPA (M0), estando em acordo com os resultados encontrados por Reimers, McGarrity e Strickland ${ }^{17}$ que concluíram que as concentrações basais de cortisol não foram afetadas pelo jejum por 36 horas em cães. Pode-se também afirmar que o manuseio do paciente, o despertar pós-anestésico e colheita por venopunção não foram capazes de produzir uma típica resposta ao estresse com liberação de cortisol. As concentrações de cortisol não acompanharam os valores glicêmicos, sugerindo possível ação do sistema nervoso simpático nos valores da glicemia, no período de recuperação anestésica.

No presente estudo, $100 \%$ dos animais apresentaram conteúdo sólido ausente (escore 1) a partir de 18 horas de jejum pré-anestésico, confirmando os resultados encontrados por Arnbjerg ${ }^{8}$, em que o estômago se apresentou completamente vazio após 14 a 16 horas da alimentação seca em cães, a partir do que recomendou um período de jejum mínimo de 16 a 20 horas para garantir o trato gastrintestinal completamente vazio.
Baseado neste estudo experimental é possível concluir que: os animais com 12 horas de jejum pré-anestésico apresentaram glicemia mais elevada do que aqueles submetidos a jejum de 18 e 24 horas, no período de recuperação anestésica, apesar dos valores de glicemia pré-anestésica terem sido normais em todos os diferentes tempos de jejum; a duração do jejum pré-anestésico não interferiu nas concentrações séricas de cortisol no momento pré, trans e pósanestésico; o jejum pré-anestésico sólido, independente do tempo de duração, caracterizou um quadro de discreta alcalose respiratória; todos os animais apresentaramse em bom estado clínico nos três grupos; a anestesia geral inalatória com halotano em cães pré-tratados com acepromazina e tiopental sódico provocou poucas alterações cardiocirculatórias e respiratórias não havendo interferência dos diferentes períodos de jejum pré-anestésico.; recomenda-se jejum sólido pré-anestésico mínimo de 18 horas para garantir ausência completa de conteúdo alimentar sólido no estômago e, portanto, evitar risco de regurgitação e aspiração de conteúdo sólido.

\section{Agradecimentos}

À FUNDUNESP pelo apoio financeiro, à $\mathrm{CNPq}$ pela bolsa concedida durante o mestrado e à Premier ${ }^{\text {Pet }}$, Fort Dodge Saúde Animal e COVELI pelo fornecimento de rações, vacinas e vermífugos aos animais do estudo.

\section{Correlation of the diferent fasting periods with serum cortisol, plasma glycemia, condition clinic and acid-base balance in dogs submitted to inhalation of general anaesthesia}

\section{Abstract}

This study correlated the solid preoperative fasting periods with plasma glycemia, serum cortisol, condition clinic and acid-base balance in dogs submitted to inhalation of general anaesthesia. Eight adults, animals were distributed into three groups in accordance with solid preoperative fasting: group 1 (12 hours), group 2 (18 hours) and group 3 (24 hours). Gastric emptying was observed and following this animals were submitted to the same anesthetic procedure. Heart and respiratory
Key words: Cortisol. Glycemia. Acid-base balance. Fasting. Dog. 
rate, rectal temperature, capillary refill time, percent hydration and noninvasive arterial pressure determined before and after Acepromazine and every 10 minutes during anaesthesia, included ETCO $_{2}$; values blood gas ( $\mathrm{pH}, \mathrm{PaCO}_{2}, \mathrm{PaO}_{2}, \mathrm{HCO}_{3}, \mathrm{TCO}_{2}, \mathrm{SaO}_{2}$, $\mathrm{BE})$, glycemic and serum cortisol were analyzed before MPA and each 30 minutes during anaesthesia. In recovery anaesthetic, glycemia and serum cortisol were repeated. During anaesthesia there were little cardiovascular and respiratory alteration not having interference of the preoperative fasting periods. Animals with 12 hours of the preoperative fasting showed a higher rise in glycemia levels than others groups in recovery anaesthetic. Serum cortisol wasn't influenced by fasting. Solid preoperative fasting independent of the duration describe a discreet respiratory alkalosis. All animals showed good clinical condition in all three groups. Solid preoperative fasting of the 18 hours is recommended to ensure a complete absence of the solid food contents in stomach.

\section{Referências}

1 GALATOS, A. D.; RAPTOPOULOS, D. Gastro oesophageal reflux during anaesthesia in the dog: the effect of preoperative fasting and premedication. The Veterinary Record, v. 137, n. 4, p. 479-483, 1995.

2 GREEN, C. R.; PANDIT, S. K.; SCHORD, M. A. Preoperative fasting time: is the traditional policy changing? Results of a national survey. Anesthesia and Analgesia, v. 83, n. 1, p. 123-128, 1996.

3 LUNA, S. P. L. Equilíbrio ácido-básico. In: FANTONI, D. T.; CORTOPASSI, S. R. G. Anestesia em cães e gatos. São Paulo: Roca, 2002. p. 120-129.

4 MAEKAWA, N. et al. Effects of 2-, 4- and 12-hour fasting intervals on preoperative gastric fluid $\mathrm{pH}$ and volume, and plasma glucose and lipid homeostasis in children. Acta Anaesthesiologica Scandinavica, v. 37, n. 8, p. 783-787, 1993.

5 NOGUEIRA, L. C. et al. Efeitos do jejum alimentar pré-cirúrgico sobre a glicemia e o período de recuperação anestésica em cães. Brazilian Journal of Veterinary Research and Animal Science, v. 40, p. 2025, 2003. Suplemento 1.

6 FRIESEN, R. H.; WURL, J. L.; FRIESEN, R. M. Duration of preoperative fast correlates with arterial blood pressure response to halothane in infants. Anesthesia and Analgesia, v. 95, n. 6, p. 1572-1576, 2002.

7 PICKRELL, J. A. et al. Influence of fasting on blood gas tension, $\mathrm{pH}$, and related values in dogs. American Journal of Veterinary Research, v. 34, n. 6, p. 805808, 1973.

8 ARNBJERG, J. Gastric emptying time in the dog and cat. Journal of American Animal Hospital Association, v. 28, n. 1 , p. 77-81, 1992.

9 AMBRÓSIO, A. M. Anestesia e sistema digestório. In:
FANTONI, D. T.; CORTOPASSI, S. R. G. Anestesia em cães e gatos. São Paulo: Roca, 2002. p. 260-270.

10 EVANS, A. T. Anesthetic emergencies and accidents. In: THURMON, J. C.; TRANQUILLI, W. J.; BENSON, G. J. (Ed.). Lumb \& Jones' veterinary anesthesia. 3rd. ed. Baltimore: Williams \& Winkins, 1996. p. 849860 .

11 HARDY, J. F. Large volume gastro-esophageal reflux: a rationale for risk reduction in the perioperative period. Canadian Journal of Anaesthesia, v. 35, n. 7, p. 162 173, 1988.

12 PHILLIPS, S.; DABORN, A. K.; HATCH, D. J. Preoperative fasting for paediatric anaesthesia. British Journal of Anaesthesia, v. 73, n. 4, p. 529-536, 1994.

13 CHEIBUB, Z. B. Respostas endócrinas à anestesia. Revista Brasileira de Anestesia, v. 41, n. 5, p. 357-367, 1991.

14 REDFNER, N.; ADDISON, G. M.; MEAKIN, G. Blood glucose in anaesthetized children. Comparison of blood glucose concentrations in children fasted for morning and afternoon surgery. Anaesthesia, v. 41, n. 3, p. 272-275, 1986.

15 TAYLOR, P. M. Equine stress response to anaesthesia. British Journal Anaesthesia, v. 63, n. 6, p. 702-709, 1989.

16 WALT, J. H. V.; CARTER, J. A. The effect of different pre-operative feeding regimens on plasma glucose and gastric volume and $\mathrm{pH}$ in infancy. Anaesthesia and Intensive Care, v. 14, n. 4, p. 352-359, 1986.

17 REIMERS, T. J.; MCGARRITY, M. S.; STRICKLAND, D. Effect of fasting on thyroxine, 3, 5, 3'triiodothyronine, and cortisol concentrations in serum of dogs. American Journal Veterinary Research, v. 47, n. 12, p. 2485-2490, 1986. 